Australian Journal of

Educational Technology

\title{
How successful is "Successmaker"? Issues arising from an evaluation of computer assisted learning in a secondary school
}

Judy M. Parr

University of Auckland

\begin{abstract}
The paper discusses issues arising from the year long evaluation of the use of the computer assisted learning (CAL) package "Successmaker" in a secondary school (Years 8-12). All students in Year $8(n=199)$ and Year 9 $(\mathrm{n}=180)$ had equal access to the computer assisted learning lab for an hour session a week. Specialised groups like learning support, special education and ESL also used the lab for blocks of time. Multiple sources of data were used to assess the process and outcomes of introducing CAL. Issues arising include whether the rationale for such a program is well founded; its effectiveness, including cost effectiveness and generalisability of learning, and the question of educational integrity in terms of curriculum and pedagogical appropriateness.
\end{abstract}

The rationale for introducing an integrated computer assisted learning (CAL) package like "Successmaker" (1) into a school is likely to be multidimensional. For the principal of the secondary school where the evaluation of "Successmaker" took place (2), the main reason was to help address the issue of under-achievement in literacy and numeracy by a significant proportion of students. The main mechanisms by which successful outcomes might be achieved were considered to be the interest value of the medium, whereby students may be more prepared to tackle work; individualisation allowing instruction and practice at an appropriate level, and the experience of success which would result from this. Computer assisted learning, as Apple (1991) comments, is often seen as an approach to the problems of under achievement and relevance, 
although Apple questions whether it is part of the solution or part of the problem. This paper will examine the use of "Successmaker" as a solution and raise some of the problematic issues.

Cognitive learning research (eg. Beck, Perfetti \& McKeown, 1982; Schneider \& Schiffrin, 1977) suggests that, in order to perform complex intellectual tasks such as reading and mathematical problem solving, many of the subskills have to be automated. Practice is the way to achieve this. The concept of practice is entrenched in pedagogy; basic facts and table drills in maths and sending books home to read are examples from the early school years. Computer assisted learning delivers practice examples most efficiently; the computer is infinitely patient in the presentation of example after example until mastery is attained. Although practice can be delivered efficiently via CAL, the question of effectiveness remains.

Most of the sample of 63, Year 8 students interviewed during the evaluation of "Successmaker" were positive about CAL. A number (26) commented on the interesting or different or fun nature of the work. For ten of these students it was enjoyable simply because they did not have to write - "It's better just to push the buttons. Here you have more time and relax". Another commented "It's more interesting than you do in class; there's graphics and things like that". However, for some, interest was detrimentally affected by features of the program like repetition and pace. "Boring" was a favoured descriptor, offered by nearly a third of the interviewees. When probed, it seemed to be either that the student readily grasped the concept but had to do a minimum number of examples before progressing ("I hate it when you really know the stuff but it keeps coming up") or that, despite not having mastered an idea, the student found the presentation of more of the same tedious ("The questions repeat over and over" and "They have a lot of one sort of question, not a variety").

Although the material presented in the strands (3) based programs is individualised and varies according to ability, a few teachers felt that for some able students the progression was too slow and the work insufficiently challenging. Student comment supported this: "You have to work through all the programs. It's easy but it takes too long and it gets boring". It is possible for teachers to adjust levels manually but this requires that the teacher learn to recognise the need for intervention in a novel situation and to use different sources of diagnostic information. Besides ability differences among students, there are likely to be 
significant individual differences in saturation level in terms of tolerance for continued examples of a similar kind. In the classroom, the skilled teacher avoids tedium by finding a new format to practise the same skill or by changing focus and coming back to the difficult area later. A "Successmaker" course like "Maths concepts and skills", hierarchically organised on mastery principles, is less flexible.

Practice is most effective in meaningful, relevant contexts. A criticism of "Successmaker" and similar CAL programs is that the practice does not take place in such contexts. The fact that technology, in the form of a computer, is used to deliver the content does not render the work automatically meaningful, despite parental beliefs that their offspring were learning "relevant things" about computers through using "Successmaker". Nor, as is often naively assumed, does the use of the computer per se, with its associations with the work place, with amusement and "hi-tec", encourage students to have more favourable attitudes to learning. In a study which examined the effects of personal laptop computer use on attitudes and achievement, Morrison, Gardner, Reilly and McNally (1993) found that the positive impact of high access to computers on attitude to school and to a subject area was marginal. Positive associations occurred where the process based work on the computer was seen to transfer directly to the content domain of the discipline. The implication is that the work done on the CAL program has to bear direct relevance to the associated curriculum area. Teachers in the evaluation found most satisfactory those sections within the maths program like "number basics" which paralleled the syllabus for Year 8. Students, too, based many of their favourable comments about their progress on the CAL maths unit concerning measurement, which matched the curriculum closely.

In the evaluation school, "Successmaker" was largely utilised within an existing, successful learning support curriculum framework. The educational integrity of any innovation is dependent on the extent to which it complements and extends curricula goals and melds with the school's philosophy of teaching and learning and accepted pedagogical models. Some of the teachers interviewed felt that the dominant pedagogical approach of "Successmaker" (risking over simplification as there are a variety of different courses, it could be described as 
individualised instruction based on mastery learning principles) was not sound; others commented that it did not blend readily with their classroom practice, which often included cooperative work, while others acknowledged that the approach of the software was different to theirs but it made for variety. Research suggests that different preferences with respect to learning styles, like the finding that girls prefer a social situation, may mean that students benefit differentially from computer assisted learning (Hattie \& Fitzgerald, 1987). However, the data from the evaluation show that girls made more rapid progress than boys and there was no difference ethnic groups.

One pedagogical feature which some staff and students commented positively on was the fact that computer assisted learning allowed students to take responsibility for their own learning. Researchers (eg. Clarke, 1990) have commented on the fact that one of the appealing features of CAL is its opportunity for control. Students, in the interviews, in outlining what they liked about CAL, commented on a perceived lack of teacher monitoring and control. This reaction was particularly marked among the learning support students (low achievers) and may reflect some of their experiences of education to date. In reality, the students controlled neither content nor pace to any extent. But, the pattern in the lab was established; they did not need teacher direction to begin or to log in to the system. They had some, limited choice about what area to begin work on. They recorded their own progress scores as they completed a unit. Teachers commented that students felt that the feedback from the program was objective and they were more ready to acknowledge their weaknesses.

Thus, the teacher's role may change with the use of computer assisted learning. Ideally, computer assisted learning with provision for individualised instruction and practice should allow the teacher more flexibility to help, particularly those less able students. Schofield and Verban (1988) found in a CAL situation that teachers shifted away from concentrating on better students to the point where the weaker students received four to five times as much attention. But teachers need time and, possibly, guidance to adapt their role to this new learning situation. In some cases (Asker, Yavuz \& Koksal, 1992), the reported help from teachers was less during CAL than in the traditional classroom. Classroom 
observation during the evaluation and the fact that few teachers utilised the diagnostic features of "Successmaker" supports the view that teachers have to adjust to a new role which includes, amongst other things, developing a new set of criteria for assessing on-task behaviour and new strategies for monitoring the process of practice and learning outcomes.

With a large suite of programs such as "Successmaker", written from a United States curriculum perspective, many teacher hours also need to be devoted to exploring the offerings in order to best utilise the material effectively. As a maths teacher noted, "The material on "Successmaker" is organised in a different way (to the Year 8 syllabus) in that on "Successmaker" you get several things at once while our curriculum is in blocks". Some teachers saw the possibility of the software for "ongoing, systematic maintenance". This pattern of utilisation requires careful planning and monitoring in terms of timing to complement the curriculum yet satisfy individual needs and duration to find the optimum exposure time. Both the need for curriculum match and the necessity for training and guidance, alluded to above, certainly need to be borne in mind when assessing cost effectiveness, as does the observation, discussed below, that those who made the greatest absolute gains not only had most time on the system (in addition to normal class time in the subject area) but a most favourable student teacher ratio, half that of normal classes.

The foremost consideration, in respect to effectiveness, is does the instruction and practice delivered via CAL lead to enhanced learning outcomes? Students experienced success within "Successmaker". The most successful were those who had intensive time and were within small learning support classes, staffed by dedicated and expert teachers. Working at their own level certainly allowed students to achieve in terms of the objectives and criteria of the particular program within "Successmaker". If the results of Year 8 and Year 9 classes are averaged, students gained, for every hour spent working on CAL, 1.25 months of school learning in maths and 3.1 in reading. This is in excess of the claims made for the software (that of one month of school learning per hour on the program), although it should be remembered that these gains are occurring while the normal school program is in operation and over a time period and so are confounded by normal developmental gains.

Those students who made the greatest absolute progress (although at a slower rate) were the learning support students, students in the lowest 
percentiles for literacy and numeracy on nationally normed tests. These students received intensive work on CAL (four hours a week over a term and often a further term), working closely with their learning support maths or English teacher in classes of 12 to 15 . The outcome was basically that they progressed at a rate more approaching average rather than the slow rate of progress they had exhibited over previous schooling. On going, longitudinal research would be necessary to establish whether these students would catch up with their cohort or simply not fall further behind and whether they would need to continue with intensive work to achieve this.

Partly as a result of experiencing success, but perhaps also because they felt they had some control over the process, many students developed more positive perceptions of themselves as learners. They were achieving at their own level and felt pleased with their progress "on the computer". Some of the comments, at interview, suggested there were other spinoffs in terms of a more confident approach to learning in the normal classroom. Comments such as "Now in class I can understand things better" and "It's helped me when I have normal maths" suggest a transfer of learning. And several teachers were able to nominate specific skills students had acquired and transferred. However, the perception of generalisation of learning from CAL to classroom was not borne out by the achievement data. Results with respect to generalisation of learning in maths, for example, to school based tests were statistically insignificant although the trend was in the expected direction.

There are other issues to consider when a school is looking at a costly piece of software like "Successmaker". These include questions of equity. Does a school aim for equality of access or is the consideration equity in terms of outcomes, a goal which suggests that those most in need receive the most? The evaluation school tried to give all Year 8 and 9 access by apportioning time equally to all classes. But, as the primary aim was to help those in Year 8 needing most assistance in literacy and numeracy, these students received intensive time. This decision had to be made within the constraints that the license cost of the software was linked to the number of machines.

A consideration of the balance sheet in order to assess the success of "Successmaker" shows it, like the rationale for the introduction of CAL, to be multi-dimensional. Students undoubtedly make progress on the program, yet there is no strong evidence of generalisation. Those 
underachieving in literacy and numeracy begin to achieve at a rate approaching the average but the resource input, both in terms of CAL time and teacher time, is great. In any consideration of cost effectiveness this, plus teacher development and teacher time to effect integration, need to be weighed against other viable alternatives. The majority of students like CAL; there is evidence of positive affective outcomes. Administering the correct "dose" is, however, a delicate and vitally important aspect. Pedagogical features of the program are questioned by some staff and students and there is a clear need to investigate this and the question of curriculum match further.

\section{Notes}

1. "Successmaker" is the name under which a suite of computer assisted learning programs, covering the curriculum areas of maths and science,reading, language skills, basic competency, and computer education, are marketed. The programs are produced by the Computer Curriculum Corporation, a division of Simon and Schuster, USA.

2. A detailed report of the evaluation is contained in Parr (1994).

3. Courses are either strands where the student works through hierarchically organised sets of content/skill areas or lessons which may be selected to cover specific skills or content. For example, "Maths concepts and skills " is a course with 16 different strands, including addition, decimals, fractions etc. An example of a lesson is "The use of the apostrophe".

\section{References}

Apple, M. (1991). The new technology: Is it part of the solution or part of the problem in education? Computers in the Schools, 8(1/2/3), 59-81.

Askar, P., Yavuz, H. \& Koksal, M. (1992). Students' perceptions of computer assisted instruction environment and their attitudes towards computer assisted learning. Educational Research, 34(2), 133-139.

Beck, I., Perfetti, C. \& McKeown, M. (1982). The effects of long-term vocabulary instruction on lexical access and reading comprehension. Journal of Educational Psychology, 74, 506-521. 
Clarke, V. (1990). Sex differences in computing participation: Concerns, extent, reasons and strategies. Australian Journal of Education, 34(1), 5266.

Hattie, J. \& Fitzgerald, D. (1987). Sex differences in attitudes, achievement and use of computers. Australian Journal of Education, 31(10), 3-26.

Morrison, H., Gardner, J., Reilly, C. \& McNally, H. (1993). The impact of portable computers on pupils' attitudes to study. Journal of Computer Assisted Learning, 9,130-141.

Parr, J. (1994). Evaluation of the computer assisted learning project at Rutherford High School. Wellington, New Zealand: Ministry of Education.

Schneider, W. \& Schiffrin, R. (1977). Controlled and automatic human information processing: II. Perceptual learning, automatic attending and a general theory. Psychological Review, 84, 127-190.

Schofield,J. \&Verban, D. (1988). Computer use in mathematics teaching: Issues which need answers. In D. Grouws \& T. Cooney (eds), Effective mathematics teaching, Vol 1, pp 169-193. Hillsdale, NJ: Erlbaum.

Contributor: Dr Judy Parr currently teaches and researches in the Education Department at the University of Auckland. A cognitive/ developmental psychologist, her present research interests include issues in the development of written language and in the use of technology in the teaching and learning process. Her address is Education, University of Auckland, Private Bag 92019, Auckland, New Zealand. Email jm.parr@auckland.ac.nz

Please cite as: Parr, J. M. (1995). How successful is "Successmaker"? Issues arising from an evaluation of computer assisted learning in a secondary school. Australian Journal of Educational Technology, 11(1), 20-27.

http: / / www.ascilite.org.au/ajet/ajet11/parr.html 